\title{
THE GENETIC CONTROL OF SELF-INCOMPATIBILITY IN THE GENUS GASTERIA (LILIACEAE)
}

\author{
P. E. BRANDHAM and S. J. OWENS \\ Jodrell Laboratory, Royal Botanic Gardens, Kew, Richmond, Surrey TW9 3DS, England
}

Received 25.vii.77

\section{Summary}

\begin{abstract}
The results of intercrossing 11 fertile $F_{1}$ individuals obtained from an interspecific cross between two self-incompatible species of Gasteria, viz. G. liliputana and $G$. humilis, reveal that at least two genes control the self-incompatibility reaction. The site of pollen tube inhibition in incompatible matings is confirmed as the ovule.
\end{abstract}

\section{Introduction}

SelF-ingompatibility is known to occur in many species of the family Liliaceae (Fryxell, 1957), but an analysis of its genetic control has been attempted only in one instance, by Brewbaker and Gorrez (1967) in an $\mathrm{F}_{1}$ interspecific hybrid in the genus Gasteria. They considered that their data were consistent with an incompatibility system controlled by alleles at a single $\mathrm{S}$ locus acting gametophytically in the pollen. This interpretation will be discussed fully later in the light of our own results.

A survey is under way in our laboratory on the cytotaxonomy of the tribe Aloineae (Liliaceae), one aspect of which is the production of a large number of bispecific and bigeneric hybrids. A few crosses were made between $F_{1}$ plants in order to study the segregation of particular genes governing morphological characters, and in one instance it was noted that the $\mathrm{F}_{2}$ progeny frequently contained large numbers of albinos (Brandham, 1977). During an investigation into the inheritance of albinism a diallel was carried out involving eleven $F_{1}$ plants obtained from a cross between two species of Gasteria. It was noted that the $\mathrm{F}_{\mathbf{1}}$ plants displayed an unexpectedly high incidence of cross-compatibility, and the results of this diallel and their significance are the subject of this article.

\section{Material and methods}

The $F_{1}$ plants were obtained from a cross made in 1970 between two very dissimilar diploids $(2 n=14)$. The female parent was Gasteria liliputana v. Poelln. (accession no. 68-97), and the male parent was $G$. humilis v. Poelln. (accession no. 68-554). The eleven $\mathrm{F}_{1}$ hybrid individuals used in the diallel were between 6 and 7 years old and were numbered as shown in table 2. Stages of meiosis in parents and $F_{1}$ hybrids were observed in squashes of fresh anthers in 2 per cent aceto-orcein. For the estimation of pollen fertility in $F_{1}$ plants fresh pollen was stained in 1 per cent propionic carmine on a slide. Stained (presumed fertile) and unstained or misshapen (presumed non-viable) grains were scored from four batches of 100 grains in each case, and were averaged to give a percentage fertility. 
Crosses were made between the $F_{1}$ individuals in 1976 and 1977 during the months of March and April. No isolation of flowers was attempted, firstly because insect visitation is negligible at this time and secondly because although all $11 \mathrm{~F}_{\mathbf{1}}$ plants were grown close together and flowered at the same time no spurious capsules were formed by unprotected flowers. These observations indicated that the risk of contamination or accidental crosspollination is minimal. In all cases, with the exception of a late-flowering individual (71-2878) a minimum of three and a maximum of nine flowers were used to test each pollination in the diallel. For 71-2878 as female the results are represented by only a single pollinated flower in each cross.

All pollinations were made on flowers approximately 2 days after opening, pollen being obtained from the anthers of newly-opened flowers only. Each cross was marked with coloured cotton tied round the pedicel and recorded. After an incompatible mating the flower falls about 8 days from pollination. After a compatible mating the ovary is visibly swollen within 6 days. Capsules ripen in 6 to 8 weeks.

\section{Results}

\section{(i) Meiotic analysis of parents and $F_{1}$}

Meiosis in pollen mother cells of both parents and the $11 F_{1}$ hybrid individuals was normal, with seven bivalents being produced, a result supported by the high stainability percentages of the pollen of the $F_{1}$ plants (see table 2). There was no evidence of major structural differences between the chromosomes of the two species, either in the form of interchange or inversion hybridity in the $F_{1}$. A very few E-type bridges were observed at anaphase $\mathrm{I}$ in some hybrids, indicating a slight degree of structural hybridity (Brandham, 1969).

\section{(ii) Self-incompatibility and the site of pollen tube inhibition}

The flowers of all Gasteria species are markedly protandrous. The style elongates after anther dehiscence, growing through the anthers clustered in the corolla tube, and the stigma becomes liberally coated with pollen. This pollen germinates and the pollen tubes grow down the style to the ovules but no seed is set. Since this always occurs and the plants never produce spurious capsules one can assume their self-incompatibility. Controlled self-pollinations were carried out in every $F_{1}$ hybrid, a total of 40 flowers, and all were confirmed to be self-incompatible.

Examination of pollen tube growth on selfing shows that pollen tubes enter the ovary. Many tubes were seen to be associated closely with ovules, but none was seen to penetrate.

\section{(iii) Seed set}

The results of repeated cross-pollinations between three $F_{1}$ individuals are shown in table l. The percentage of successful pollinations is remarkably uniform at between 44.4 per cent and 55.5 per cent. No spurious capsules were formed by flowers which were not cross-pollinated. 
TABLE 1

The frequency of successes in multiple pollinations between three compatible $F_{1}$ plants of the cross between Gasteria liliputana and $\mathrm{G}$. humilis

$\begin{array}{cccc}\begin{array}{c}\text { Cross } \\ \text { female } \times \text { male) }\end{array} & \begin{array}{c}\text { No. of flowers } \\ \text { pollinated }\end{array} & \begin{array}{c}\text { No. of capsules } \\ \text { formed }\end{array} & \begin{array}{c}\text { \% successful } \\ \text { pollinations }\end{array} \\ 71-2876 \times 71-2877 & 27 & 12 & 44 \cdot 4 \\ 71-2877 \times 71-2876 & 9 & 5 & 55 \cdot 5 \\ 72-152 \times 71-2876 & 28 & 13 & 46 \cdot 4 \\ \text { Totals } & 64 & 30 & 46.9\end{array}$

(iv) $F_{1}$ diallel

The results in table 2 show that with few exceptions all $F_{1}$ plants are reciprocally cross-compatible. The three exceptions are 71-2876 pollen on 71-2883 (10 flowers attempted) and pollen from 72-1184 and 74-221 on 71-2878. The last two failures were each represented by only one pollination because of the late flowering of 71-2878, and might have been successful if more crosses had been possible ( $\mathrm{cf}$. table $\mathrm{l}$ ) but the first-listed failure indicates a true case of unilateral compatibility, since the reciprocal cross was successful.

\section{TABLE 2}

The results of selfing and intercrossing $11 F_{1}$ plants of the cross Gasteria liliputana $\times \mathrm{G}$. humilis

\begin{tabular}{|c|c|c|c|c|c|c|c|c|c|c|c|c|c|}
\hline & \multicolumn{11}{|c|}{ Female } & \multirow{2}{*}{$\begin{array}{c}\text { Pollen } \\
\text { fertility } \\
(\%)\end{array}$} \\
\hline & & $\begin{array}{c}71 \\
2467\end{array}$ & $\begin{array}{c}71 \\
2876\end{array}$ & $\begin{array}{c}71 \\
2877\end{array}$ & $\begin{array}{c}71 \\
2878\end{array}$ & $\begin{array}{c}71 \\
2883\end{array}$ & $\begin{array}{c}71 \\
2884\end{array}$ & $\begin{array}{c}72 \\
152\end{array}$ & $\begin{array}{c}72 \\
1184\end{array}$ & $\begin{array}{c}72 \\
1191\end{array}$ & $\begin{array}{r}74 \\
221\end{array}$ & $\begin{array}{r}74 \\
222\end{array}$ & \\
\hline \multirow{11}{*}{ Male } & $\left(\begin{array}{ll}71 & 2467\end{array}\right.$ & - & + & + & + & + & + & + & + & + & + & + & 89 \\
\hline & 712876 & + & - & + & + & - & + & + & + & + & + & + & 70.5 \\
\hline & 712877 & + & + & - & + & + & + & + & + & + & + & + & 85 \\
\hline & 712878 & + & + & + & - & + & + & + & + & + & + & + & 83 \\
\hline & 712883 & + & + & + & + & - & + & + & + & + & + & + & 70 \\
\hline & 712884 & + & + & + & + & + & - & + & + & + & + & + & 84 \\
\hline & $72 \quad 152$ & + & + & + & + & + & + & - & + & + & + & + & $88 \cdot 5$ \\
\hline & $72 \quad 1184$ & + & + & + & - & + & + & + & - & + & + & + & $84 \cdot 5$ \\
\hline & $72 \quad 1191$ & + & + & + & + & + & + & + & + & - & + & + & 91 \\
\hline & 74221 & + & + & + & - & + & + & + & + & + & - & + & 83 \\
\hline & $74 \quad 222$ & + & + & + & + & + & + & + & + & + & + & - & $93 \cdot 5$ \\
\hline
\end{tabular}

\section{Discussion}

The data obtained in the diallel (table 2) of this Gasteria bispecific hybrid can be satisfactorily explained on the basis of at least two multi-allelic genes controlling the self-incompatibility reaction for the following reasons:

a. Eleven intra-incompatible, inter-compatible groups are found in the sample of $11 \mathrm{~F}_{1}$ plants.

b. One-way compatibility occurs in at least one and possibly three crosses. 
Control of self-incompatibility by a single gene will result in four intraincompatible, inter-compatible groups in the $\mathrm{F}_{1}$, two genes will produce 16 , and three genes will produce 64 groups. Our 11 plants are all in different groups and the likelihood of their being selected randomly from 16 groups is slight $(P=0.0099)$. It is more probable that they were selected from 64 groups $(\mathrm{P}=0.4021)$. Thus it is possible that the incompatibility system in Gasteria is controlled by more than two genes, but until we can obtain further data we cannot claim categorically that more than two exist.

The failure of the parents to flower at the same time as the $\mathbf{F}_{\mathbf{1}}$ plants, and the site of pollen tube inhibition making observations of half-compatibilities impossible using existing methods (Watkins, 1925 Lundquist, 1961) prevented confirmation of the gametophytic nature of the reaction. However, considerable support for its gametophytic control comes from a recent paper by Lewis (1977). As part of his argument that control of the incompatibility system in Eruca sativa can be most satisfactorily explained on the basis of at least three genes controlling a sporophytic system, he compares the results obtained for the Eruca families with the expected results when the control of incompatibility is by two or three genes in a gametophytic system. Though the results on Eruca are completely at variance with a gametophytic system, our results, which show only non-reciprocal incompatible matings, are totally in accord with such a system.

Our finding a control by a minimum of two genes was totally unexpected, because Brewbaker and Gorrez (loc. cit.) obtained data in another group of bispecific $\mathrm{F}_{1}$ hybrids of Gasteria which they considered were consistent with control of self-incompatibility by a single multi-allelic gene acting gametophytically in the pollen. Examination of their results reveals, however, that they do not fit exactly into the one-locus hypothesis. Indeed, the presence of more than the four intra-incompatible, inter-compatible groups characteristic of a one-locus system can be seen in their findings. Furthermore, 12 of their crosses showed reciprocal differences. Undoubtedly the crux of the matter lies in the ability of the $\mathbf{F}_{\mathbf{1}}$ hybrid to set seed since Brewbaker and Gorrez (loc. cit.) stated "inconsistencies among repeated crosses were encountered, reflecting largely the irregular performance of certain crosses as male or female parents". The $F_{1}$ hybrids in our case were very pollenfertile (table 2), yet even in these a seed set of only about 50 per cent was encountered in a set of known compatible crosses (table 1).

There is much to be discussed, since our results have shown firstly that a multigenic incompatibility system, which was previously known in the monocotyledons only in the Gramineae (Lundquist, 1975 Spoor, 1976), occurs in the genus Gasteria (Liliaceae) and secondly that the site of incompatible pollen tube inhibition is the ovule, which confirms the previous work of Sears (1937) and Brewbaker and Gorrez (loc. cit.). Yet judgment and discussion are being reserved since we are dealing with a hybrid situation which might have introduced complications connected with undetected structural heterozygosity. Work has already begun on a diallel using about $50 \mathrm{~F}_{1}$ individuals of an intra-specific cross involving the genus Aloe, which is closely related to Gasteria, and early results indicate that a similar incompatibility system might exist within a single species in this group of plants.

Acknowledgment.-We are indebted to Dr M. J. Lawrence for advice on statistics. 


\section{REFERENGES}

BRAndham, P. E. 1969. Chromosome behaviour in the Aloineae I. The nature and significance of E-type bridges. Chromosoma (Berl.), 27, 201-215.

BRANDhAM, P. E. 1977. The inheritance of leaf pigmentation in Gasteria. Kew Bull., 32, 13-17.

BREWBAKER, J. L., AND GORREZ, D. D. 1967. Genetics of self-incompatibility in the monocot genera, Ananas (Pineapple) and Gasteria. Amer. 7. Bot., 54, 611-616.

FRYXELL, P. A. 1957. The mode of reproduction in higher plants. Bot. Rev., 23, 135-233.

LEWIs, D. 1977. Sporophytic incompatibility with 2 and 3 genes. Proc. R. Soc. Lond. B., $196,161-170$.

LUNDQUIST, A. 1961. A rapid method for the analysis of incompatibilities in grasses. Hereditas, 47, 705-707.

LundQUIST, A. 1975. Complex self-incompatibility systems in Angiosperms. Proc. R. Soc. B., $188,235-245$.

SEARS, E. R. 1937. Cytological phenomena connected with self-sterility in flowering plants. Genetics, 22, 130-181.

sPOOR, w. 1976. Self-incompatibility in Lolium perenne L. Heredity, 37, 417-421.

WATKINS, A. E. 1925. Genetical and cytological studies in wheat. 7. Genet., 15, 323-366. 